University of Navarra

\title{
COMPETING THROUGH BUSINESS MODELS
}

\author{
Ramon Casadesus-Masanell \\ Joan E. Ricart
}

IESE Business School - University of Navarra

Avda. Pearson, 21 - 08034 Barcelona, Spain. Tel.: (+34) 932534200 Fax: (+34) 932534343

Camino del Cerro del Águila, 3 (Ctra. de Castilla, km 5,180) - 28023 Madrid, Spain. Tel.: (+34) 913570809 Fax: (+34) 913572913

Copyright ${ }^{\circledR} 2007$ IESE Business School. 


\title{
COMPETING THROUGH BUSINESS MODELS
}

\author{
Ramon Casadesus-Masanell ${ }^{1}$ \\ Joan E. Ricart ${ }^{2}$
}

\begin{abstract}
In this article a business model is defined as a company's choice of policies and assets, the governance structure of those policies and assets, and their consequences, whether flexible or rigid. We also provide a way to represent such business models to highlight dynamic loops and to facilitate an understanding of the interaction with other business models. Furthermore, we develop some tests to evaluate the business model both in isolation as well as in interaction with other business models from different organizations, such as competitors, complementary organizations, suppliers, partners, and others.
\end{abstract}

\footnotetext{
${ }^{1}$ Professor, General Management, Harvard Business School

2 Professor, General Management, IESE
}

Keywords: Business model, Interaction, Competitive Strategy, Competitive Dynamics. 


\section{COMPETING THROUGH BUSINESS MODELS*}

Business model innovation is becoming one of the main forces driving strategic renewal efforts of businesses around the world. IBM's 2006 "Global CEO Study," for example, shows that top management in a broad range of industries are actively seeking guidance on how to innovate in their business models to improve their ability to both create and capture value.

While the expression "business model" has been a part of business jargon for a long time, there is no widely accepted definition of what it really means. Its origins can be traced back to the writings of Peter Drucker (1954), but the notion has only gained prominence among both academics and practitioners in the last decade or so. This is not to say that organizations did not have or use business models prior to this recent wave of interest, but rather that, because business models of industry players were for the most part similar, the business model did not receive the attention that it does today.

Advances in information and communication technologies have driven the recent interest in business model design and business model innovation. Many of the so-called "e-businesses" constitute new business models (Evans and Wurster, 1997; Varian and Shapiro, 1999). Shafer, Smith, and Linder (2005) present twelve recent definitions of business model and find that eight are related to e-business. Of course, not all business model innovations are IT-driven; other forces such as globalization and deregulation have also resulted in new business models and fuelled the interest in this area.

New strategies for the bottom of the pyramid in emerging markets (Ricart et al., 2004) have also steered researchers and practitioners towards the systematic study of business models. Most academics working in this area agree that, for companies to be effective in such "different" environments, they need to develop novel business models (Prahalad and Hart, 2002; London and Hart, 2003). In fact, socially motivated enterprises that aim to reach the bottom of the pyramid constitute an important source of business model innovations (Hart and Christensen, 2002; Prahalad, 2005).

It is certainly not controversial to state that, in order for organizations to thrive, managers must have a good understanding of how business models work. Nevertheless, the academic community has so far offered little insight on this issue. In truth little is understood about what constitutes a superior business model, or even what a business model really is. This chapter attempts to remedy this state of affairs.

\footnotetext{
* We thank Giambattista Dagnino, Pankaj Ghemawat, Costas Markides, Jan Rivkin, and seminar participants at IESE's "Brown Bag" Seminar series and the 2007 Meetings of the Academy of Management (Philadelphia). Casadesus-Masanell is grateful to the HBS Division of Research and IESE Business School's Public-Private Sector Research Center.
} 


\section{What Is a Business Model?}

Although there is no generally accepted definition of business model, practitioners and academics often talk loosely of a business model as "the way the company operates." While we share this view to an extent, we must provide a more specific definition to make progress. To this end, we review existing work and base our definition on earlier notions.

Magretta (2002) defines business models as "stories that explain how enterprises work." This author goes back to Peter Drucker and defines "a good business model" as the one that provides answers to the following questions:

- Who is the customer and what does the costumer value?

- What is the underlying economic logic that explains how we can deliver value to customers at an appropriate cost?

Magretta's implicit idea is that the term "business model" refers to the logic by which the organization earns money. While not formal, Magretta's approach highlights two fundamental questions that any business model should answer: one related to the value provided to the client and the other to the organization's ability to capture value in the process of serving customers.

While Magretta's definition is broad and imprecise, Amit and Zott's (2001) is narrow (as it focuses on e-businesses) but precise. These authors review the contributions of several theories including virtual markets, Schumpeterian innovation, value-chain analysis, the resource-based view of the company, dynamic capabilities, transaction cost economics, and strategic networks. As they point out, every theory contributes elements to the notion but none, by itself, completely explains the nature of business models. Amit and Zott analyze a sample of U.S. and European e-business models to highlight the drivers of value creation and present the following integrated definition: "A business model depicts the content, structure, and governance of transactions designed so as to create value through the exploitation of business opportunities" (page 511). Transaction content refers to the goods or information being exchanged, as well as to the resources and capabilities required. Transaction structure refers to the parties that participate, their links, and the way they choose to operate. Finally, transaction governance refers to the way flows of information, resources, and goods are controlled by the relevant parties, the legal form of organization, and the incentives to the participants.

As mentioned above, Shafer, Smith, and Linder (2005) uncovered twelve definitions published from 1998 to 2002, and they developed an affinity diagram to identify four major categories common to all or most definitions: strategic choices, creating value, capturing value, and the value network. Therefore, consistent with the intuitive view of the concept, a business model is defined by strategic choices, sometimes made by a network of organizations, that explain value creation and value capture.

From this we conclude that an important component of business models are the specific choices made by management on how the organization must operate. For example, choices regarding things such as compensation practices, procurement contracts, location of facilities, assets employed, extent of vertical integration, or sales and marketing initiatives are, for the most part, choices made by management that define "the way the company operates." 
Choices, however, are not the sole constituent of business models. As all authors highlight, choices must be connected to value creation and value capture, or to alternative goals the company may want to pursue. And just as causes have effects in the physical world, management choices have consequences. For example, the provision of high-powered incentives (a choice) has implications regarding the willingness to exert effort or to cooperate with coworkers (consequences). Likewise, pricing policies (choices) have obvious implications regarding sales volume, and this, in turn, affects the economies of scale and bargaining power enjoyed by the company (two consequences). Because consequences (such as low cost or a culture of frugality) are usually employed to describe "the way the company operates," we include them in our definition of a business model.

In summary, a business model consists of: (1) a set choices and (2) the set of consequences arising from those choices.

For the purposes of illustration, and somewhat loosely, think of a company as a machine. ${ }^{1}$ of course, real organizations are different from machines in many important respects but, as will become clear below, the comparison is useful. In this analogy, a business model refers to how the machine is assembled ("choices" on how the machine is put together) and how the different elements work together ("consequences" of the choices). A machine may be constructed in an almost infinite number of ways, with different levels of redundancy, specific mechanisms, quality of components, and so on. Furthermore, different machine configurations have different direct consequences, and this affects the overall level of efficiency (speed, input efficiency, noise, quality of output, etc.).

It is useful to distinguish different types of choices and consequences. There are three types of choices: policies, assets, and governance of those policies and assets. Consequences, on the other hand, are classified into either flexible or rigid.

\section{Figure 1}

Elements of a Business Model

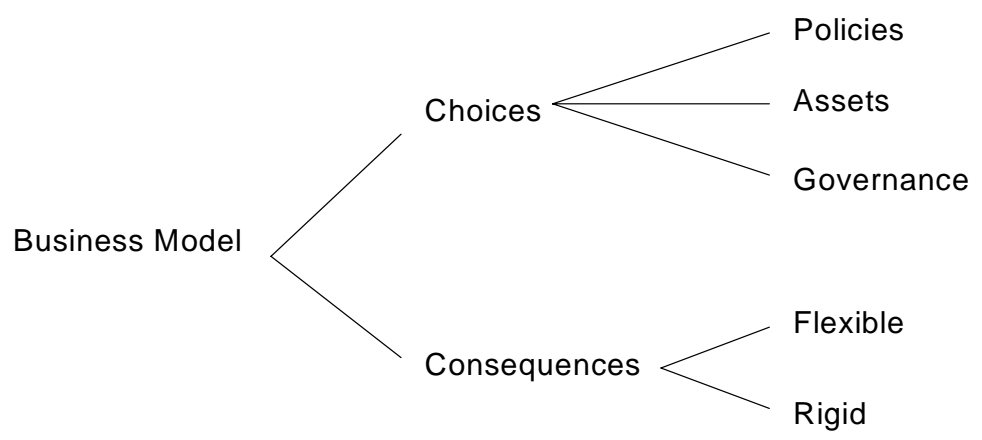

In this model, the element "Policies" refers to courses of action adopted by the company regarding all aspects of its operation. Examples of policies include opposing the emergence of unions, locating plants in rural areas, encouraging employees to fly tourist class, providing high-powered monetary incentives, or flying to secondary airports. "Assets" (physical) refers to tangible resources such as manufacturing facilities or a satellite system for communicating

\footnotetext{
${ }^{1}$ Indeed, for-profit organizations are often referred to as "money-making machines.“
} 
between offices. ${ }^{2}$ The element "governance" refers to the structure of contractual arrangements that confer decision rights regarding policies or assets. For example, a given business model may contain as a "choice" the use of certain assets such as a fleet of trucks. The fleet can be owned by the company or leased from a third party. As literature on transaction cost economics shows (see, for example, Williamson, 1980), seemingly innocuous differences in governance of assets and policies may have dramatic effects on the effectiveness of a given business model.

A consequence is flexible if it is sensitive to the choices that generate it. For example, large volume is a consequence of a policy of low prices. If the policy changes to high prices, volume is likely to fall rapidly. In contrast, a rigid consequence is one that does not change rapidly with the choices that generate it. For example, a "culture of frugality" is a consequence that changes only slowly with the choices that generate it. Perhaps a more tangible example is an "installed base of PCs" which is (partly) a consequence of prices set by Intel and Microsoft for the microprocessor and the operating system, respectively. As prices change, the installed base changes slowly: it is a rigid consequence. Clearly, no consequence is purely flexible or purely rigid. All consequences are somewhere in between; it is a matter of degree.

\section{Business Model Representations}

A useful way to represent business models is by means of a causal-loop diagram (Baum and Singh, 1994): choices and consequences linked by arrows representing causality. However, except possibly for the simplest organizations, such a representation rapidly becomes highly complex and often intractable. In principle, one could make the effort of listing every choice made by management (although this would take a very long time). More difficult, perhaps, is to list the set of all consequences of those choices and to spell out exactly how choices (and different combinations of choices) deliver those consequences, and how exactly consequences (and different combinations of consequences) enable choices. In most businesses there are large numbers of choices and consequences. An analysis and evaluation of an organization's business model that takes into consideration every choice and every consequence is just impractical: nothing meaningful can be concluded by considering choices and consequences in full richness of detail.

To overcome this issue, we work with representations of business models (or models of business models). A business model representation consists of (i) choices (generally a subset of all choices), (ii) consequences (generally a subset of all consequences), and (iii) theories.

Notice the third element: theories. Theories are suppositions on how choices and consequences are related. For example, a theory may be that as R\&D expenses increase, products with innovative features are brought to market. In the causal loop diagram, we would have an arrow from "high R\&D expenses" to "innovative products." In many cases theories are commonly accepted relationships open to little discussion. ${ }^{3}$ Other times, however, "theories" are controversial. In the 1960s, Sam Walton believed that large volumes of merchandise would be

\footnotetext{
2 Notice that intangible assets such as experience, brand equity, or even the value of patents are consequences (generally rigid), not choices.

${ }^{3}$ Notice that disciplines such as economics, sociology, or psychology are, for the most part, devoted to generating theories. For example, there is a large body of economic literature devoted to understanding how incentives affect performance. These theories are distilled in our business model representation by use of a simple arrow (or a few arrows) connecting choices and consequences. Disciplines look at the arrows with great care, but have little concern about how arrows interact with one another and contribute to making the whole of a business model.
} 
bought in rural areas if discount stores were located there. At the time, most people did not share this view. (See Bradley, Ghemawat, and Foley, 1994.)

Notice also that theories do not appear in the definition of a business model. A business model is made up of choices and consequences, but these are the actual choices and actual consequences as they are truly related. The term "business model" refers to the real relationships. A business model representation, on the other hand, refers to a model of the business model. A business model representation integrates theories of causality that are believed to be true by the business model designer or analyst. If later they fail to hold up, there will be a break in the logic leading to business model failure (partial or complete).

As mentioned above, we do not include every choice and consequence in the business model representation. There are two main ways to move from the full, true detail of a business model to a simplified, tractable representation: aggregation and decomposability. In most instances, business model representations make simultaneous use of both approaches.

Aggregation. Aggregation works by bunching together detailed choices and consequences into larger constructs. For example, specific incentive contracts (which may be unique to every individual in the organization) may be bunched together into a choice called "high-powered incentives." This captures the idea that contracts typically impose high-powered incentives on the workforce. In the business model representation, instead of detailing every contract offered to every individual, we simply write one choice: high-powered incentives. This allows a simplified representation that enhances our understanding of the organization.

One can think of aggregation as 'zooming out' and looking at the (real) business model from the distance. As the analyst zooms out, details blur and larger objects (aggregations of details) become clear. If one keeps one's nose too close to every choice and consequence, it is impossible to see the larger picture and understand how the business model works. On the other hand, if one looks at the business model from very far away, all the interesting details are lost. It is more of an art than a science to find the right distance from which to assess a given business model. How much to 'zoom out' generally depends on the question the analyst is trying to address.

In what follows we use the expression "level of aggregation" to refer to the extent to which we zoom out from the full business model. A high level of aggregation refers to looking at the business model from a long distance. A low level of aggregation refers to being close to the details. As we point out below, high levels of aggregation are needed when analyzing interaction between business models of different players (or competition through business models).

Decomposability. Sometimes business models are decomposable in the sense that different groups of choices and consequences do not interact with one another and thus can be analyzed in isolation. In this case, depending on the question to be addressed, representing just a few parts of an organization's business model may be appropriate. Clearly, this simplifies the analyst's task considerably. For example, in the case of Ryanair developed below, there are few interactions between Ryanair's choices on related businesses such as car rentals or accommodation, or on ancillary business by others, and therefore Ryanair's operative choices related directly to the management of the airline. Given this, one can understand the working of Ryanair's model without needing to be absolutely comprehensive. 
Decomposability also allows the study of individual business units in multi-business organizations. For example, below we represent Microsoft's business model for operating systems and productivity applications for the PC (at a high level of aggregation). Microsoft is present in many other sectors such as videogame systems or operating systems for personal digital assistants. Although there are interactions between all of these businesses, these may not be central to the particular question being addressed by the analyst and may therefore be ignored.

In what follows, we will abuse language and refer to business model representations as, simply, business models. In doing this, we are assuming that the representation does a good job of portraying the organization's true business model.

\section{An Example: Ryanair}

To illustrate our notion of a business model, consider Ryanair in 1999 as described in Rivkin's (2000) classic. Important choices in Ryanair's business model include: low fares, flying to secondary airports, all passengers treated equally, nothing is free, no meals, short-haul flights, standardized fleet of Boeing 737s, low commissions to travel agencies, non-unionized, highpowered incentives, and Spartan headquarters. Consequences of those choices include: low variable and fixed costs, reputation for reasonable fares, combative management team, large volume, etc. Considering what we know about the industry, we can develop theories on how choices and consequences are related. For example, an arrow from low fares (choice) to high volume (consequence) reflects the theory that the demand function for flights is downwardsloping. We employ a causal loop diagram to represent Ryanair's business model. (See Figure 2.)

\section{Figure 2}

Ryanair's Business Model

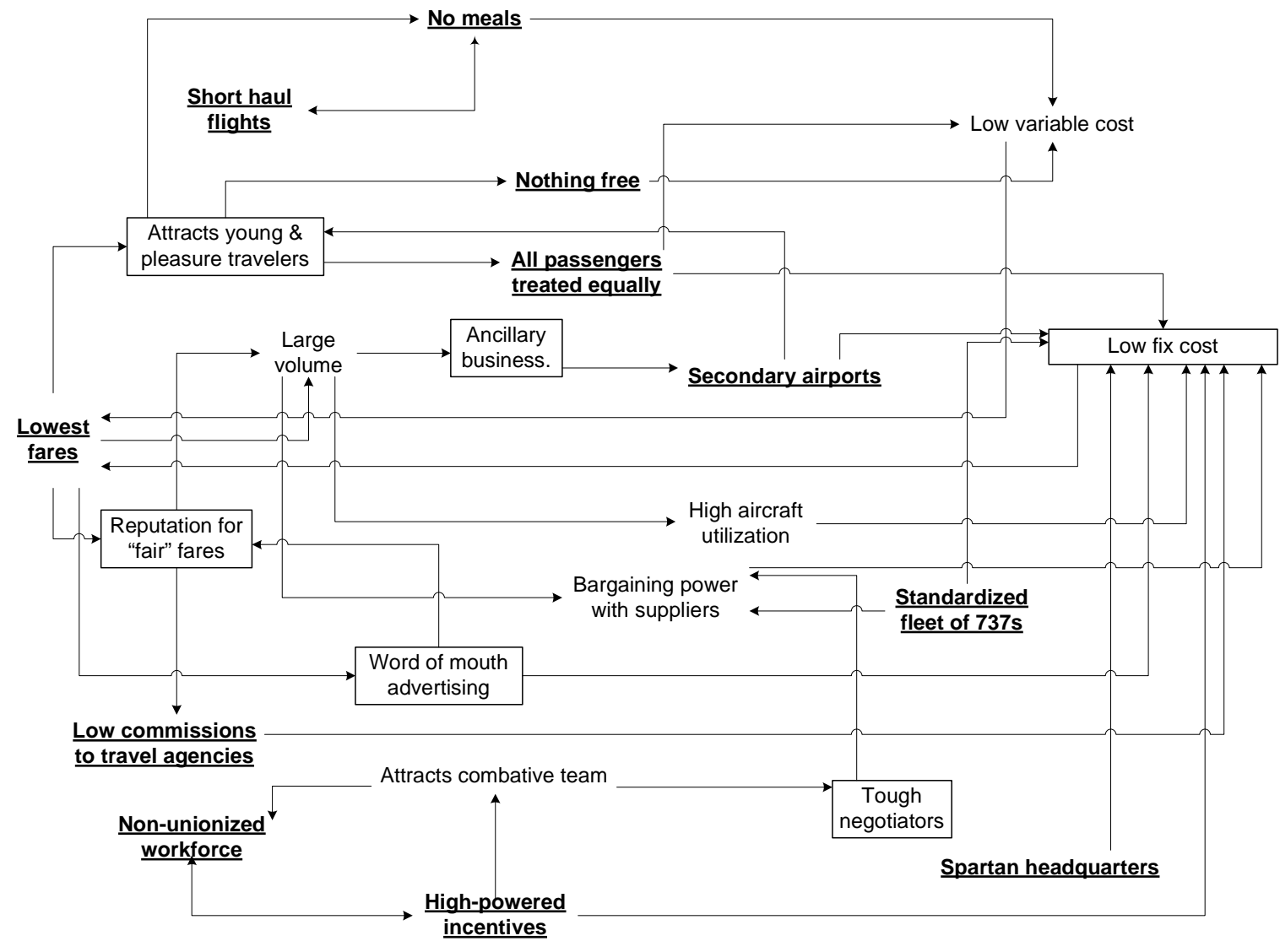

6 - IESE Business School-University of Navarra 
Choices are in bold and underlined, rigid consequences are in boxes, and flexible consequences are plain text. Notice that the representation does not include every choice made by Ryanair nor every consequence. We have made use of aggregation and decomposability.

Figure 3 is a representation of Ryanair's business model with theories. To explicitly account for theories, we include a short text with the justification for each arrow. To keep the representations simple, however, in the rest of the paper we will place the arrows without explicit theories. Only when a theory is not obvious will it be written down because, as Figure 3 illustrates, when theories are explicitly accounted for, the diagram becomes harder to read.

\section{Figure 3}

Ryanair's Business Model with Theories

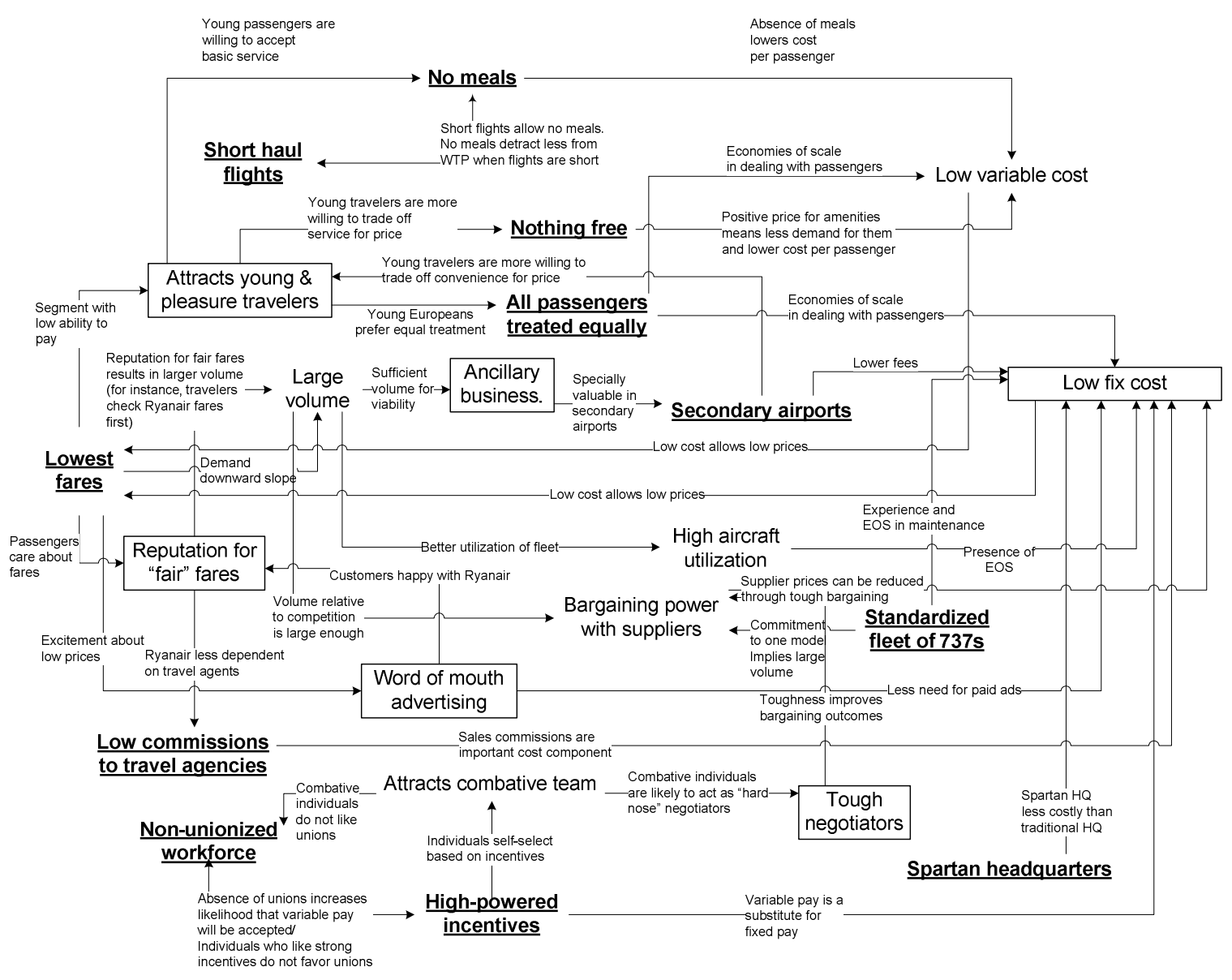

In summary, the causal loop diagram represents theories linking choices and consequences that allow us to conjecture that Ryanair is able to offer service at a very low cost without reducing too much the customers' willingness to pay in the target segment.

We should point out that the absence of arrows also implicitly defines theories. For example, Ryanair's choices of a standardized fleet and the use of secondary airports are unrelated, even if they may reinforce one another by leading to low maintenance costs and rapid turnovers. 
However, the assumption is that these choices are independent. For simplicity, in the diagram above, we do not spell out these "absent arrow" theories.

\section{Virtuous Cycles - The Dynamics of Business Models}

By now, it should be apparent that our concept of a business model is intrinsically dynamic. The relationship between choices and consequences occurs over time. Moreover, some "rigid" consequences are stocks (such as an installed base or cumulative experience) that are built over time. An understanding of the functioning and evaluation of business models requires explicit consideration of the dynamics between choices and consequences.

One of the most striking features of business models is that their dynamics often generate feedback loops. This happens when, in addition to choices yielding consequences, consequences enable choices. Feedback loops can be of two types: virtuous cycles and vicious cycles. Since these are symmetric, and the same principles therefore apply to both, we need to study one type of feedback loop and have chosen to focus on virtuous cycles.

Virtuous cycles are feedback loops that, with every iteration, strengthen some components of the model at every iteration. For example, Honda historically set low prices for its motorcycles (a choice); the consequences were high volume and high cumulative output which allowed the company to move down the learning curve, and thus result in low cost. Low cost (a consequence), in turn, enabled Honda to profitably set low prices (a choice). As the cycle spun again and again, Honda kept lowering prices because (marginal) cost decreased. ${ }^{4}$ Using the representation diagram:

\section{Figure 4}

Example of a Virtuous Cycle

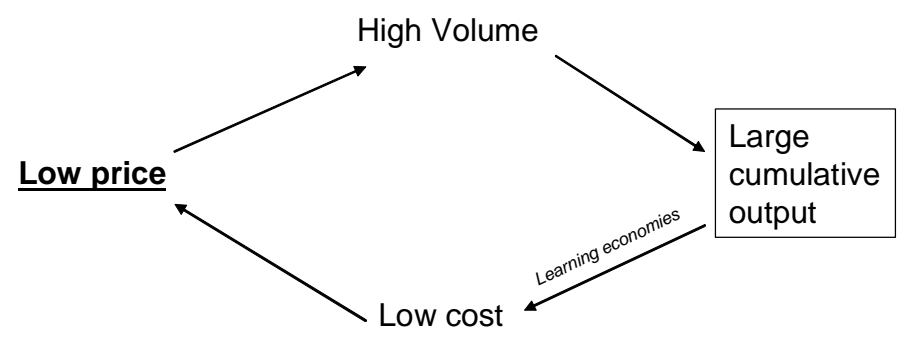

Virtuous cycles are feedback loops that, with every iteration, strengthen the value of the components of the model.

Once they get going, virtuous cycles take on a life of their own; just as a fast-moving body is hard to stop because it possesses kinetic energy, ${ }^{5}$ well-functioning virtuous cycles cannot easily be brought to a halt.

\footnotetext{
${ }^{4}$ See Christiansen and Pascale (1983).

${ }^{5}$ Kinetic energy is the energy that a body possesses by virtue of its movement.

8 - IESE Business School-University of Navarra
} 
Virtuous cycles are especially desirable when they affect the growth of consequences related to goals that the company seeks to accomplish. For example, Figure 3 shows that Ryanair's business model possesses many important virtuous cycles that lead to low cost. The following are examples of virtuous cycles in Figure 3 that "pass through" low cost, one cornerstone of Ryanair's model:

- Cycle 1: lowest fares $\rightarrow$ large volume $\rightarrow$ bargaining power with suppliers $\rightarrow$ low fixed costs $\rightarrow$ lowest fares $\rightarrow$...

- Cycle 2: lowest fares $\rightarrow$ large volume $\rightarrow$ high aircraft use $\rightarrow$ low fixed costs $\rightarrow$ lowest fares $\rightarrow \ldots$

- Cycle 3: lowest fares $\rightarrow$ large volume $\rightarrow$ ancillary businesses develop $\rightarrow$ fly to secondary airports $\rightarrow$ low fixed costs $\rightarrow$ lowest fares $\rightarrow$...

- Cycle 4: lowest fares $\rightarrow$ attracts young and pleasure travelers $\rightarrow$ nothing free $\rightarrow$ low variable costs $\rightarrow$ lowest fares $\rightarrow$...

- Cycle 5: lowest fares $\rightarrow$ attracts young and pleasure travelers $\rightarrow$ all passengers treated equally $\rightarrow$ low costs $\rightarrow$ lowest fares $\rightarrow$...

- Cycle 6: lowest fares $\rightarrow$ attracts young and pleasure travelers $\rightarrow$ no meals $\rightarrow$ low variable costs $\rightarrow$ lowest fares $\rightarrow$...

As we discuss below, a desirable feature of business models is the generation of virtuous cycles that move the organization towards fulfilling its goals, whatever those may be.

\section{Business Model Evaluation}

We have defined a business model as a set of choices and the consequences arising from those choices. Clearly, because every organization makes choices and these choices have consequences, every organization has some business model. The questions then are: What constitutes a good business model? And how can we tell a good model from a bad one?

We begin by considering business models in isolation, ignoring how they may be affected by those of other players. In other words, we consider an organization's business model in an interaction vacuum and discuss four related desirable features: alignment to goal, reinforcement, virtuousness, and robustness. We later introduce other players and provide a framework to evaluate business models in interaction. While considering business models in isolation is artificial, the analysis of business model interaction adds sufficient complexity to justify the approach.

\section{Business Model Evaluation - Analysis in Isolation}

Alignment to goal

"Alignment to goal" refers to business model choices delivering consequences that move the organization towards achieving its objectives. An organization may possess an excellent business model that works very smoothly but, if the organization's goal is different from what 
the business model delivers, then alignment to goal fails and the business model is just not appropriate.

Possible goals include, but are not limited to, profit maximization, a better environment, or a pleasant place to work. For instance, as a workers' cooperative, Irizar (see Appendix) is more concerned with the creation of value-added jobs in the Basque Country than with profit maximization. Likewise, the community of Linux developers (an "organization" that competes against Microsoft's Windows) is more concerned with adding useful new features to the operating system, its robustness, minimization of bugs, and maximization of available complements, than with cost minimization or profit maximization.

Organizations often have multiple goals. The balance between different goals may itself be a goal. Notice the trivial fact that, in most cases, goals are consequences, not choices: a company that tries to maximize profit, for instance, is not choosing profit directly; profits arise endogenously as a function of choices made by the company.

In many cases, alignment to goal is obvious. Ryanair's goal of high growth and profitability in the airline industry requires low costs. Everything in Ryanair's business model is geared towards delivering low cost. Sometimes the link is less direct. Irizar's goal of creating high added-value jobs in the Basque Country is an indirect consequence of its choices. By creating value with a differentiated product, Irizar can sustain and grow employment but no direct connections exist among Irizar's choices and that overarching goal.

Of course there are organizations that develop business models that fail to satisfy alignment to goal. Xerox Corporation, for example, set up the PARC ${ }^{6}$ lab in the 1970s as an instrument for innovation with the objective of developing new, profitable businesses. While PARC did come up with many breakthrough innovations, ${ }^{7}$ it was unable to generate new businesses and capture value from those until some thirty years later.

\section{Reinforcement}

Reinforcement refers to choices complementing each other well. Reinforcement is closely related to the well-known idea in Strategy of internal consistency. ${ }^{8}$ It is worth defining clearly what we mean by two choices complementing one another:

Let $\mathrm{A}$ and $\mathrm{B}$ be two choices. Let $\mathrm{C}$ be all other choices made by the company. Finally, let $\mathrm{o}(\mathrm{A}, \mathrm{B}, \mathrm{C})$ be a measure or score of how close the organization's goal is satisfied when choices are $\mathrm{A}, \mathrm{B}$ and $\mathrm{C}$. A higher score means better performance. Obviously, o(.) is a consequence. We say that B complements $\mathrm{A}$ if $\mathrm{o}(\mathrm{A}, \mathrm{B}, \mathrm{C})-\mathrm{o}(0, \mathrm{~B}, \mathrm{C})>\mathrm{o}(\mathrm{A}, 0, \mathrm{C})-\mathrm{o}(0,0$, C) where 0 stands for the absence of the choice. ${ }^{9}$ Our notion of 'complementarity' is local in the sense that it depends on the set $\mathrm{C}$ : $\mathrm{A}$ and $\mathrm{B}$ may be complementary given $\mathrm{C}=\mathrm{C}$, but not complementary when $\mathrm{C}=\mathrm{C} 2$. For example, suppose $\mathrm{A}$ is low price and $\mathrm{B}$ is heavy

\footnotetext{
${ }^{6}$ Palo Alto Research Center, California.

${ }^{7}$ Such as laser printing, Ethernet, and the Graphical User Interface (GUI) concept used as a front-end to almost all modern operating systems including Microsoft Windows.

${ }^{8}$ See Michael Porter, “Competitive Advantage," Free Press, 1985. See Michael Porter, "What Is Strategy?," Harvard Business Review, 1996.

9 Notice the assumption that objectives are quantifiable. Sometimes objectives are easily quantifiable (at least conceptually) such as value creation or value capture (profit maximization). Quantification is less direct in other cases. For example, one main goal of Greenpeace may be a better environment and this would be hard to measure objectively.
} 
advertising. Let $\mathrm{o}(\mathrm{A}, \mathrm{B}, \mathrm{C})$ be market share. $\mathrm{A}$ and $\mathrm{B}$ are complementary in the sense that the effect of a low price on market share is likely to be larger when there is heavy advertising. Likewise, the effect of heavy advertising on share is stronger when prices are low. In business model representations we sometimes write $A \leftrightarrow B$ to denote 'complementarity'. We do this to save time and space, as a more elaborate diagram would have the entire chain from every choice to every consequence.

An obvious example of lack of reinforcement would occur if Ryanair decided to provide a level of comfort comparable to that of full-fare carriers such as British Airways. Increasing the level of comfort would require reducing the number of seats in planes, the additional offer of food, coffee, baggage transfer, and, perhaps, flights to primary airports. These choices would undermine the low-cost structure. As a consequence, Ryanair would not be able to maintain its low fares; volume would fall, affecting incentives, economies of scale, and reputation.

As a second example, consider high-powered incentives, a choice that results in large effort exertion. A side effect of high-powered incentives is that it often results in less willingness to cooperate and help each other. In organizations with business models that do not rely on cooperation, high-powered incentives will generally be appropriate (at least for a portion of the workforce). However, at Irizar, an organization where all work is done through self-managed teams, high-powered incentives will likely lead to less cooperation between team members and/or unhealthy competition between teams. ${ }^{10}$ Absence of reinforcement implies the presence of opportunities to improve the business model by discontinuing some choices and adding new ones. Business models develop through time. Early identification of tensions due to inconsistencies is fundamental to manage their development.

\section{Virtuousness}

Virtuousness refers to the presence of virtuous cycles (positive feedback loops) that help a business model to gain strength over time. In the case of Microsoft, for example, there are two complementary virtuous cycles; the first is related to operating systems and the second to productivity applications. Virtuousness is a dynamic version of reinforcement.

Business models endowed with virtuous cycles that lead to better fulfillment of objectives often imply growth. Growth takes place as rigid consequences directly related to goals become stronger. Examples include positive feedback loops that generate bargaining power (with, say, suppliers) or network effects such as in the case of online auction sites such as eBay. We have already pointed out many of Ryanair's virtuous cycles - interestingly, many of the cycles run through low cost and low fares. As a consequence of the cyclic iteration, Ryanair finds it easier to reach its goal of low cost and high profitability.

Porter (1996) cautions managers about the "growth trap," the idea that a fixation for growth without consideration of how it furthers the development of competitive advantage may lead to deterioration of that very advantage. ${ }^{11}$ While growth, per se, may be a poor goal to pursue, an implication of virtuous business models is growth. In a sense, growth and virtuousness are indissoluble. The ultimate goal should never be growth, but rather the pursuit of a strategy that

\footnotetext{
${ }^{10}$ As Figure A2 shows, Irizar has other mechanisms such as peer-pressure (a consequence arising from specific choices such as team work or location in small town) to ensure that effort exertion is high.

${ }^{11}$ Porter, Michael, "What Is Strategy?,” Harvard Business Review, 1996.
} 
generates virtuous cycles that help the organization to create and capture increased value over time.

\section{Robustness}

Robustness refers to the ability of the business model to sustain its effectiveness over time. Ghemawat (1991) has identified four generic threats to sustainability: imitation, hold up, slack, and substitution. To check for robustness we ask: How well does the business model fend off each threat? ${ }^{12}$.

Imitation is the drive of competitors to replicate a company's successful business model. However damaging imitation may potentially be, there are reasons why business models might be hard to copy. The presence of rigid consequences is the first such reason. Rigid consequences such as experience, reputation, culture, or privileged relationships do not change rapidly with the choices that generate them. They take a long time to build. Experience, for instance, requires the accumulation of output which is time-consuming. Therefore, it may be hard for the imitator to reconfigure its choices and build rigid consequences similar to those of the focal company rapidly enough to become a viable competitor.

In the case of Ryanair one can easily see that many of its rigid consequences are difficult to replicate. Reputation for reasonable fares takes time to develop; an installed base of young/pleasure travelers is not easy to build when it must be stolen from such an aggressive incumbent; low cost deriving from airport selection and the fleet or key negotiations with some suppliers are anything but easy to develop. Clearly then, rigid consequences act as important deterrents to imitation in this case. This barrier to imitation is even stronger when rigid consequences are part of virtuous cycles that spin quickly.

A second barrier to imitation is reinforcement. A business model with many elements that are highly complementary is generally hard to imitate. A competitor intending to replicate the model must copy many choices simultaneously for them to have a comparable effect to that observed in the focal company. The reason is that 'complementarity' between A and B depends on $\mathrm{C}$ (the other choices made by the organization). Thus, to get the benefit of A and B together, $\mathrm{C}$ must also be in place. The third barrier is the mere complexity of the business model. A business model with many interacting elements may be hard to understand and replicate. Causal ambiguity may lead imitators to wrong choices and deficient imitation. Wal-Mart's business model has many important rigid consequences such as a frugal culture, a reputation for everyday low prices or large bargaining power with suppliers. Furthermore, it has many complementary virtuous cycles that reinforce one another. In addition, the model is complex. These features make Wal-Mart's model difficult to imitate.

The second threat to sustainability is holdup. Holdup refers to customers, suppliers, complementary organizations, or other industry participants capturing value created by the focal company through the exercise of bargaining power. Holdup is especially threatening when the company has invested in relationship-specific assets which make it hard to walk away or find alternative trading partners.

\footnotetext{
12 Even if competition and the context where the business model evolves are relevant to address the question of sustainability, for expositional clarity we discuss robustness here by considering the business model of the focal firm in isolation to those of other players with which it interacts. Another note is devoted to business model interaction.
} 
Protection against holdup can be developed through choices related to the governance of assets and activities. Vertical integration and/or contracting with multiple parties (both business model choices) can help avoid dependence that leads to holdup. We should point out, however, that commitments are often important components of strategy. Thus it may be impossible for a company to have a business model with no specific investments or vulnerability to holdup.

A third generic threat to robustness is slack, or organizational complacency. Protection against slack comes from the right mix of incentives and monitoring (business model choices). As mentioned above, low-powered incentives may also protect from slack if a culture of hard work (which is a rigid consequence) has been developed through other choices. The case of Irizar illustrates this point very clearly.

The last generic threat identified by Ghemawat is substitution. Substitution refers to decreased value perceived by customers because of the presence of other products. For example, air travel is a substitute for railway travel. The shuttle service between Boston and New York reduces both willingness to pay and demand for Amtrak services between these two cities. As technologies, customer needs, or regulatory barriers evolve, previously unforeseen substitutes emerge, and these are, by definition, hard or impossible to identify.

To deal well with substitution threats, successful business models often have "competitive sensors" that alert their presence. Microsoft is perhaps the clearest example of an organization that is especially good at detecting (and responding) to substitution threats. When a substitute emerges that is superior, it may be necessary to implement changes in the focal company's business model to deal with it. Business model plasticity is thus desirable. Plasticity requires the absence of rigid consequences which, as we discussed above, are desirable to deal with the imitation threat. Barriers to imitation may become important impediments to effective response to substitution, and vice versa.

Wal-Mart is an interesting case of fighting substitution, which is a fundamental threat in retailing, as different formats (such as specialty store, department store, discount store, and so on) appear to have dominated the industry at different times. Wal-Mart has sensed new ideas well, copied them quickly, and perfected them. Wal-Mart adopted the warehouse club format in the early 1980s with Sam's Clubs, a concept created by Sol Price a few years earlier with Price Club. Sam Walton moved later to super-centers, a concept invented in Europe. In the meantime Wal-Mart tested several alternative formats that it eventually discontinued. ${ }^{13}$

Zara provides an interesting counter-example to the idea that the presence of rigid consequences implies that a business model is ill-suited to respond to the substitution threat. ${ }^{14}$ One important rigid consequence in Zara's business model is the organization's ability to learn customers' preferences and respond to them in real time by coming up with new designs that are manufactured immediately. This rigid consequence allows Zara to sense and respond to and thus deal with substitute products better than traditional clothing chains such as The Gap or Benetton. Notice that this consequence helps Zara respond to product substitution threats, but not necessarily to business model substitution.

\footnotetext{
${ }^{13}$ See Stephen Bradley and Pankaj Ghemawat, “Wal*Mart Stores, Inc.," Harvard Business School Case 794-024.

${ }^{14}$ For a detailed description of Zara's business model, see Pankaj Ghemawat and José Luis Nueno, "ZARA: Fast Fashion," Harvard Business School Case 703-497.
} 


\section{Business Model Effectiveness}

The effectiveness of a business model is measured by the extent to which it satisfies the four evaluation criteria outlined above: alignment to goal, reinforcement, virtuousness, and robustness. To end the section on analysis in isolation, we discuss some features of Ryanair's business model that deliver effectiveness. First, reinforcement and virtuousness are satisfied as there are many virtuous cycles and no vicious cycles. Because there are redundant virtuous cycles, if any one cycle is threatened by competitors' actions, there are many other cycles that ensure that profitability is protected. Second, many of the virtuous cycles pass through "low fares," "large volume," and "low cost," three elements directly related to profitability, which is Ryanair's main goal.

Third, there are many rigid consequences making imitation difficult. A virtuous cycle made up of flexible consequences can be more easily disrupted than one with rigidities. The use of secondary airports, for example, promotes the development of ancillary services such as transportation to the city (for example, since Ryanair's arrival in Girona - a city some 100 kilometers [60 miles] from Barcelona - a bus service has been established from Barcelona city center to the airport, coordinated with Ryanair's departures and arrivals, and priced at just $€ 11$ ). A simple lowering of competitors' fares does not make these ancillary services disappear. The word-of-mouth advertising that takes place because of the very low fares that Ryanair offers does not vanish immediately if competitors also lower their prices.

A significant holdup problem may arise in airlines if pilots get together to request higher pay. Ryanair's choices, such as avoiding unions or having high powered incentives, and consequences, such as the culture of high productivity that it has developed, makes hold up and slack less likely for Ryanair than to traditional flag-carriers, adding to robustness. Finally, while substitution is possible by, for example, high speed trains connecting cities served by Ryanair, the fact that its fares are extremely low together with having few delays (a consequence of choices such as flying to secondary airports or having a standardized fleet of 737s) make substitution less harmful than to full-fare airlines serving similar routes.

\section{Business Model Evaluation - Analysis in Interaction}

Having discussed the evaluation of business models in isolation, we now move to the study of business models in interaction. The effectiveness of a business model depends to a large extent on the design of business models of other players with which it interacts. Business models do not operate in a vacuum. For example, the success of Linux is not only dependent on the organization of open source software development and distribution, but also on how Linux's business model interacts with that of Microsoft. Microsoft's business model makes possible some actions that affect the ability of Linux to grow to exploit network effects.

Notice first that business model interaction can potentially be very complex. To the intricacy of business models in isolation (with their multiple choices and consequences) there is the added complexity of how choices affect consequences of other players and how choices of other players affect the focal organization's consequences. As we discussed above, business models considered in isolation are almost always so complex that we have to make use of aggregation and decomposition in our representations so that we have tractable objects to work with. The analysis of business model interaction is much more involved because, in addition to the full richness of business models, there is the full richness of interactions. 


\section{Strategy, Tactics, and Business Model}

We adopt the notion of strategy introduced by Porter (1996). According to Porter (p. 68), "strategy is the creation of a unique and valuable position, involving a different set of activities." Thus, a company's strategy results in a particular set of choices which, together with their consequences, constitutes a business model. In other words, a strategy is a (contingent) plan of action, one where the elements of choice are policies, assets, and governance structures. The company's business model is a reflection of its strategy. For example, when the Ryan brothers were at the brink of bankruptcy in the early 90s, their strategy was to transform their company from a standard full-service airline struggling to just be better (lower cost and better service) than existing competitors, to one radically different by adopting Southwest's no-frills model. In the mid 1990s, after the transformation, Ryanair had a new business model.

Similar to strategy, tactics are also courses of action. The difference is that the action sets available for tactics are constrained by the business model in place. That is, tactics are courses of action that take place within the bounds drawn by the company's business model. Let us say, by way of example, that Cirque du Soleil has a goal of reaching the $\$ 2$ billion revenue mark. If the plan of action to reach this goal is simply continuing business as usual (carefully selecting a number of cities where shows will be performed), we would call such a plan "tactics." The plan is tactical and not strategic because it does not require changes in the organization's business model, which is the object of strategy. In the short- and mid-terms, the organization's business model places constraints on what the company can do. The remaining scope for action is what we refer to as tactics.

To clarify the distinction between strategy, business model, and tactics, let's bring back the analogy between business models and machines introduced previously. Specifically, think of an automobile as a business model. The way the automobile is built places constraints on what the driver can do; it determines the action set for tactics. For example, a large, powerful SUV makes it hard for a driver to maneuver on the narrow streets of Barcelona's Gothic Quarter. A small, powerless compact car would make this task far less cumbersome. As a matter of fact, there are tactics possible with the compact car (such as driving through a really narrow street) that are impossible (not in the action set) with the large SUV. The shape of the automobile (an element of how the machine is built - its business model), places hard constraints on what the driver can do. At the same time, the powerful SUV allows the driver to enjoy the Pyrenees more fully than the small, powerless compact car. Imagine now that prior to operating the automobile, the driver could modify the features of the car: shape, power, consumption, noise... Such modifications would constitute strategies. In summary: the design and building of the car is strategy; the car itself is the business model; and driving the car is tactics.

Just as Porter (1996) points out, strategy requires strong leadership as it often calls for substantial trade-offs. In addition, it is usually hard to foresee all the effects that strategies have on tactics. Moreover, strategies often entail commitments that are hard to reverse. Tactics, on the other hand, are generally less consequential, easier to implement, and easier to understand. They fall many times under the responsibility of middle management. In fact, a large proportion of literature on the economics of industrial organization and game theory is devoted to the study of tactics. ${ }^{15}$

\footnotetext{
${ }^{15}$ In industrial organization and game theory, however, strategy is a contingent plan of action, regardless of whether this plan is strategic (from a Porterian point of view) or tactical (as defined above).
} 
Both strategy and tactics have deliberate and emergent elements. Consider, for example, the competition between Toyota and General Motors in the 1970s and 80s. At the beginning, both organizations were competing with similar business models but, slowly, Toyota began developing a different set of choices until reaching the so-called "lean manufacturing" model. Part of Toyota's strategy was emergent and part was the result of deliberate design.

\section{Interaction}

Intuitively, two organizations interact when performance depends on the presence of the other. Put more simply: two organizations interact when they affect one another. Interaction can be with competitors, suppliers, complementary organizations, or distributors (to mention just a few). Moreover, interaction may entail competition or cooperation and both may be for value capture or for value creation.

Following our distinction between business model, strategy, and tactics, we present two different but related concepts of interaction. Tactical interaction refers to organizations affecting each other by acting within the bounds set by their business models. In most cases, tactical interaction concerns the use of variables such as price, advertising, or R\&D intensity. The choice of these variables is constrained by the business models of the affected organizations. Strategic interaction, on the other hand, refers to organizations affecting each other by modifying their business models. Therefore, strategic interaction concerns the use of policies, assets, and governance structures to compete or cooperate.

Before discussing interaction, however, we need to present the notion of business model interdependence.

\section{Business Model Interdependence}

Business models of two companies are interdependent when some consequences are common to both companies' models. In other words, the business models of two companies are interdependent when they "touch" each other. For a concrete example, consider Microsoft and Intel's client PC businesses in the mid-1990s. The following simple representation captures the essence of the dynamics of Intel's business model (at a high level of aggregation). The representation stresses two choices: heavy investment in new generation microprocessors and relatively high microprocessor prices:

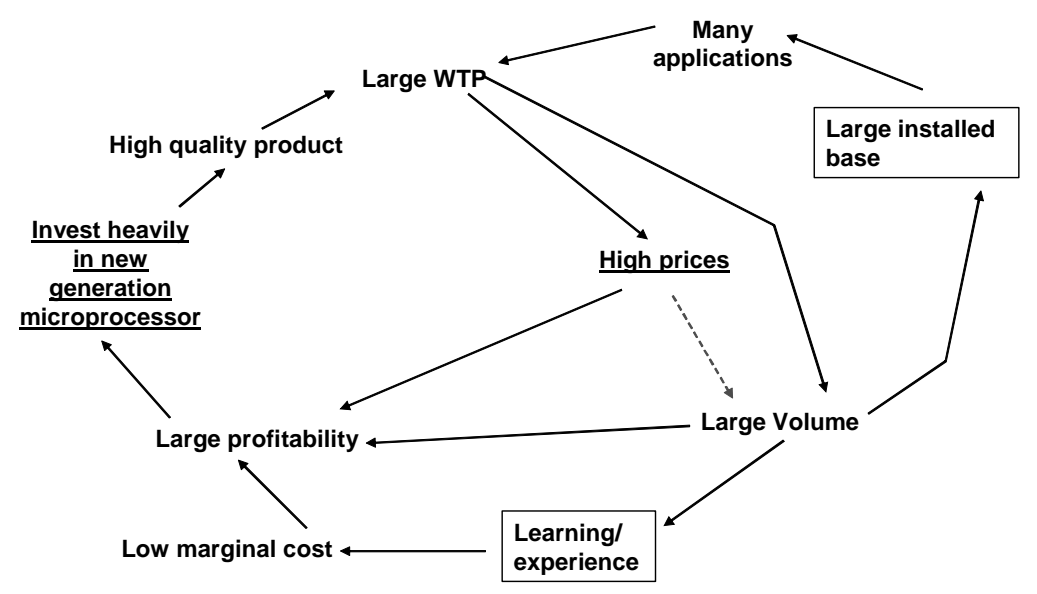

16 - IESE Business School-University of Navarra 
Microsoft's business model is fundamentally different to Intel's because in addition to deriving revenue and profit from sales of PCs (every new PC sold has a Microsoft operating system), Microsoft also derives profit from selling applications and upgrades to the installed base of PCs. The following is a high-level representation of Microsoft's business model. Choices are underlined.

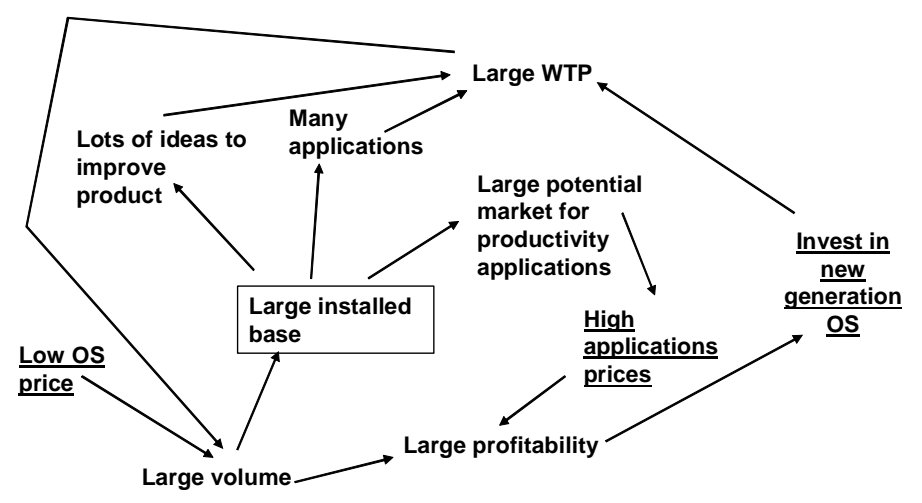

In this stylized representation we have included three main choices: investment in new generation operating systems, relatively low operating system prices, and relatively high application software prices. Notice that there are several virtuous cycles. As the installed base grows, it is increasingly difficult for competitors to catch up with Microsoft. Over time, Microsoft becomes stronger.

The diagram reveals that Microsoft has an incentive to set low prices for operating systems to grow the installed base. Microsoft then sets high prices for the applications (mainly productivity applications) and makes money from the large installed base of PCs.

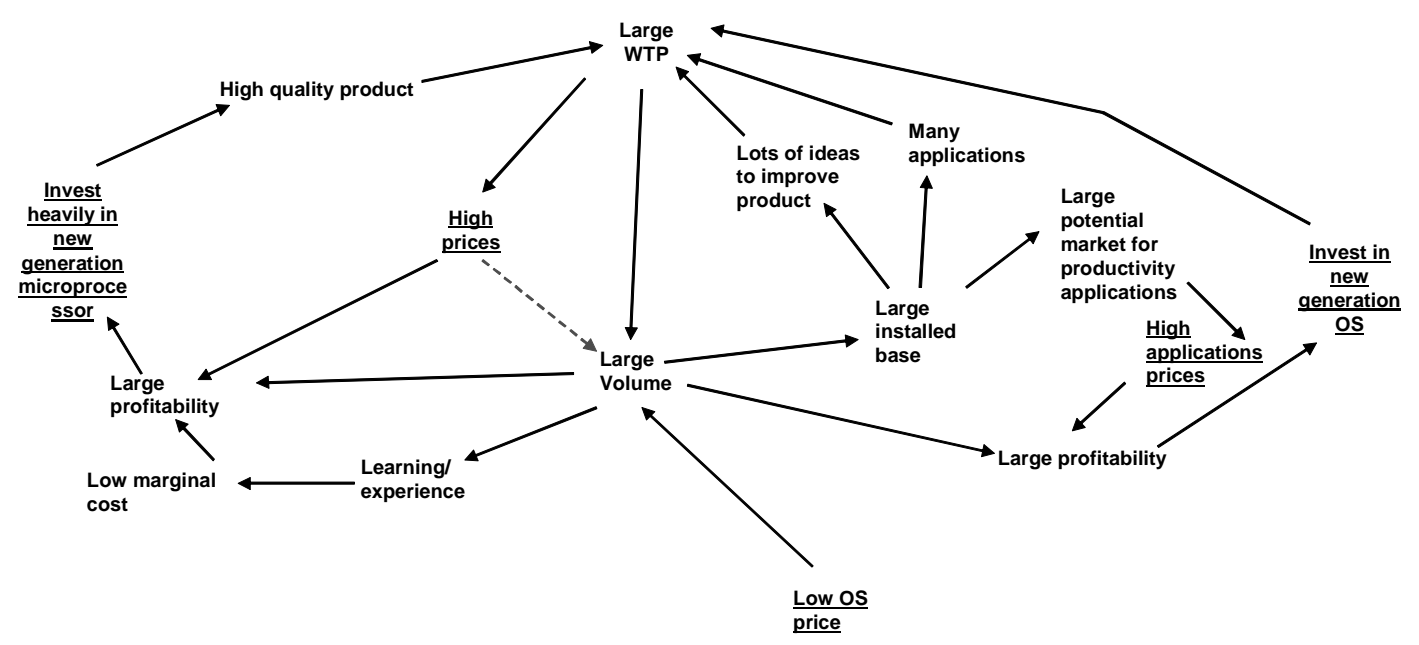

The diagram above shows that Intel and Microsoft's business models are linked together. The diagram is strictly a combination of both companies' business model representations shown previously. The linkages are: willingness to pay for the PC and volume of PCs sold. The figure makes clear that the ability of Intel's (Microsoft's) business model to generate profit depends 
not only on the design and implementation of Intel's model (Microsoft's) but also on how it interacts with Microsoft's (Intel's) model. In other words, Intel and Microsoft's business models are interdependent: Microsoft's choices (i.e., OS pricing and investment in and timing of release of new operating systems) affect the working of Intel's business model, and vice versa. ${ }^{16}$

Specifically, the volume of PCs sold at any given time depends on the prices set by Intel and Microsoft for the microprocessor and operating system, respectively. Given a willingness to pay for a PC, the more Intel charges for the microprocessor, the less value is left for Microsoft to capture through OS prices (and vice versa). This implies that there is potential conflict between Intel and Microsoft regarding pricing. Likewise, willingness to pay for a PC is highly dependent on how well Intel and Microsoft's microprocessor and operating system work together. This depends on how well Intel and Microsoft coordinate the release of new-generation processors and operating systems.

In the late 1990s and beginning of 2000s, Microsoft reduced business model interdependence with that of Intel by helping a third player, AMD, to thrive. In this new context (Intel, Microsoft, and AMD), interdependence between Microsoft and Intel became much lower (compared to when AMD was a marginal player): taking Intel out of the picture would not harm Microsoft. On the other hand, Intel's (and AMD's) level of interdependence with Microsoft's business model remained high: taking Microsoft out of the picture would render Intel and AMD's microprocessors valueless. Intel's recent support of Linux (through Intel Capital, for example) and Apple's move to Intel architecture chips should reduce the degree of interdependence between its business model and that of Microsoft. ${ }^{17}$

Another example of business model interdependence is that of "brick \& mortar" book distributors such as Barnes \& Noble (B\&N) and Internet distributors such as Amazon.com. The nature of interdependence is quite asymmetric; Amazon's business model attracts some segments of clients away from B\&N, but it also serves other markets. So we have intermediate negative interdependence of Amazon over B\&N. However, interdependence of B\&N over Amazon, while still negative, is close to zero. If B\&N disappeared, the effect on Amazon would be small.

We end this section with a summary of the main ideas. First, there is a wide array of players with which a focal company's business model may be interdependent (competitors, substitutes, complementary organizations, customers, suppliers). Two business models are interdependent if they are connected. Traditional analyses tend to focus on interdependences between competitors and, to a lesser extent, between buyers and sellers. Less attention has been given to complements (such as Intel and Microsoft) or substitutes. Second, the intensity of interdependence is endogenous as it depends on how players have decided to configure their business models. (We study this issue below when we discuss strategic interaction.) Third, interdependences may be positive or negative. Two business models may reinforce each other (cooperation) and help one another to 'work better', or they may detract from each other (competition).

\footnotetext{
${ }^{16}$ This analysis is based on Casadesus-Masanell Ramon and David B. Yoffie (2007). For more details on this example, see Casadesus-Masanell, Ramon, and David B. Yoffie, "Wintel (A), (B), (C), (D), (E), and (F) (TN)," Harvard Business School Teaching Note 706-495.

${ }^{17}$ For details on competitive interaction between Microsoft, Intel, and AMD see Casadesus-Masanell, Ramon, Barry Nalebuff, and David B. Yoffie (2007).
} 


\section{Tactical Interaction}

Tactical interaction refers to organizations affecting each other by acting within the boundaries set by their business models. If the business models of the companies under consideration are not interdependent, then there cannot be tactical interaction. The links between business models allow tactics of one company to affect the working of the other company's model. When contact points are absent, tactics have no effect on each other. Of course, even in the absence of interdependence, there is a direct effect of tactics on the organization employing them.

Aggressiveness refers to the capacity of a company to affect the working of other players' business models by use of tactics. Conversely, defensiveness refers to how well a company can fend off or take advantage of "moves" of players with which it interacts given its business model. Aggressiveness and defensiveness are generally not symmetric; indeed, when the business models of companies interacting are distinct, it is most likely that aggressiveness and defensiveness will be asymmetric. Furthermore, aggressiveness and defensiveness depend on the specific players under consideration. A's business model may result in substantial aggressiveness and defensiveness when in interaction with player B, but not when interacting with C.

Aggressiveness and defensiveness depend on the business models of the companies under consideration. There are two reasons for this. First, the breadth of tactical actions available depends on the business model. Second, the configuration of the companies' models determines the intensity of business model interdependence; and, as we pointed out above, the presence of interdependence is a necessary condition for tactical interaction.

Business model of company A is said to be consistent for a given interaction with $\mathrm{B}$, if it displays an appropriate balance between aggressiveness and defensiveness. Company A's business model is consistent (overall) if it is consistent for all relevant interactions that it may face. Consistency captures the capacity of the business model to continue being effective, taking into account the possible strategic interactions that may potentially take place.

\section{Strategic Interaction}

As mentioned above, "strategy" refers to the process of crafting an organization's business model. Thus, a strategy is a plan of action where the elements of choice are policies, assets, and governance structures. Correspondingly, strategic interaction refers to how changes in a company's business model affect the working of another company's business model.

IESE Business School, for example, may consider increasing the salary levels of Assistant Professors by, say, 20\% (as part of a new policy that alters its current business model). If this wage increase affected the workings of the business model of, say, London Business School (LBS) then we would say that there is strategic interaction between IESE and LBS (concerning IESE's wages for Assistant Professors).

Strategic interaction is concerned with the choice of policies, assets, and governance structures. And while organizations do not affect each other directly through changes in their business models, there is an indirect effect through the resulting business models as new intensity levels of interdependence and tactical interaction ensue. 
Thus, as it concerns competitive (and cooperative) interaction, there are two ways in which strategies affect outcomes. First, strategies affect the degree of business model interdependence present between any two players. In other words, business model interdependence is endogenous. ${ }^{18}$ Second, strategies determine the extent to which business models exhibit (tactical) aggressiveness and defensiveness. It is important to notice that the intensity of interdependence, aggressiveness, and defensiveness between players A and B are not chosen by A alone or B alone, but depend (simultaneously) on the strategies followed by both A and B; that is, their strategic interactions.

The following are a few of the many ways in which companies may act to reduce business model interdependence:

- Modifying your own business model so that the organization moves to spaces where there are fewer points of contact between business models. For instance, Cirque du Soleil's business model does not interact much with that of traditional circuses. The search for these spaces with few negative interactions is the key insight of Blue Ocean Strategy (Kim and Mauborgne, 2005).

- Adding elements in your business model that help other players thrive so that no one player has a large effect on the score of the focal company. Consider once again the relationship between Intel and Microsoft and think of the role played by AMD. The more AMD is a close substitute for Intel, the lower the interaction between Microsoft and Intel. In the extreme case where Intel and AMD were perfect substitutes and Intel vanished, Microsoft's 'score' would not be affected. In general, a company decreases its interdependence with a complementary organization when substitute organizations appear. Similarly, a company decreases its dependence on a key supplier when substitute suppliers appear.

Other standard ways to reduce interdependence are: keeping capacity low in commodity industries, growing the market or increasing horizontal and vertical product differentiation.

Of course, the points above can be reversed and act as two ways to increase interdependence. Increased business model interdependence is desirable when the interactions are positive (complementary). Intel Capital, for example, is the flipside of Blue Ocean Strategy in the sense that Intel is populating "the ocean" in a way that there are as many players with which it interacts as possible. The interactions in this case are complementary and therefore help all players in that ecosystem thrive.

Strategic interaction, as we have defined it, corresponds to the intuitive notion of competition through business models: modifying my own business model to affect your choices while at the same time reacting to changes in your business model.

Competition through business models is difficult to deal with. While the concept of best response is easy to define for tactics (as the action sets and payoffs are relatively easy to determine), best response functions for strategies are often very hard to figure out. The reason is that, in the case of strategies, the action spaces are huge and the interactions between different choices complex. As a consequence, it is practically impossible to come up with one's own (let alone other players') payoff functions. The implication is that strategy search is only vaguely related to classic optimization or game theory. Contrary to the case of tactics, finding

\footnotetext{
${ }^{18}$ Note that most of the literature on industrial organization assumes exogenous interdependence.
} 
appropriate strategies is much more of a creative process than one of calculation. Inspiration and imagination together with leadership are main features that strategists must possess.

The proliferation of managerial books on strategy innovation is related to the difficulty in deriving best responses. Much of the recent managerial literature on innovation is concerned with altering business models (even as it often refers to business models superficially). Yip (2004) claims that strategy practice can gain improvements by understanding business models. Recent authors such as McGrath and Mcmillan (2005) or Govindarajan and Trimble (2004) develop techniques to help companies come up with such strategies. Even authors from operations management such as Hau L. Lee (2004) point out that radical changes in some parts of a company's business model can have tremendous performance implications. At some level, this managerial literature is all about proposing avenues to make operational the Future of Competition as described by Prahalad and Ramaswamy (2004).

\section{Conclusions}

The reasons for the renewed interest in business models are clear: on the one hand, the competitive environment is becoming increasingly complex, giving rise to hyper-competition (Thomas and D'Aveni, 2004), which is characterized by difficulties in sustaining competitive advantage as new business models substitute for established ways to compete. In addition, the recent revolution in information and communication technologies opens broad opportunities to configure choices in radically different ways (Malone, 2004). Enablers of new business models are becoming readily accessible in an environment where business model innovations are increasingly important for survival.

Companies experiment and learn to change and transform their business models to adapt to the needs of complex new competitive environments (Rindova and Kotha, 2001). Companies are increasingly looking at the periphery for innovative ideas (Foster and Kaplan, 2001). In this coevolution of companies, competitors, complementary organizations, and environment (Lewin and Volberda, 1999), it is necessary to emphasize exploration over exploitation (March, 1991). As companies are increasingly forced to explore, they must become more entrepreneurial. The essence of entrepreneurship is the design of effective business models.

Entrepreneurship is all about discovering (and exploiting) existing opportunities and/or creating such opportunities. For example, Ryanair wanted to exploit the opportunities created by air traffic deregulation in Europe, but discovered the hard way (approaching bankruptcy in 1991) the need to use an unconventional business model. Alternatively, some entrepreneurs create an opportunity by inventing new business models. This is the case of Irizar's Koldo Saratxaga as described in the appendix. Pressed to recover Irizar from bankruptcy and, at the same time, keep high-value jobs in the Basque Country, Koldo invented a radically new business model.

To sum up, companies face a tough environment where innovation and entrepreneurship is fundamental. Our concept of business model is a tool for managers to deal with these complexities. We have developed a notion of business model and introduced a method for representation. We have also introduced criteria to evaluate their effectiveness in isolation. Finally, we have presented an approach to study the complex interactions between business models of different players. In summary, we have developed a set of tools to understand the process of business model innovation, competition, and cooperation. We hope that the ideas in this chapter will help managers to better face this difficult but fundamental task. 


\section{References}

Amit, R. and C. Zott (2001), "Value Creation in e-Business," Strategic Management Journal, 22, pp. 493-520.

Andrews, Kenneth (1971), “The Concept of Corporate Strategy,” Dow-Jones Irwin.

Baum, JAC. and JV. Singh (1994), "Organization-Environment Coevolution," chapter 18 in "Evolutionary Dynamics of Organizations", Baum, JAC. and JV. Singh (eds.), Oxford University Press, N.Y.

Bower, Joseph (1972), “Crown Cork \& Seal and the Metal Container Industry,” HBS case 9-373-077.

Bradley, Stephen, Pankaj Ghemawat, and Sharon Foley (1994), “Wal-Mart Stores, Inc.," HBS case 794-024.

Brandenburger, Adam and Barry Nalebuff (1996), "Co-opetition," Currency-Doubleday, New York.

Brandenburger, Adam and Harborne Stuart (1996), "Value-based Business Strategy," Journal of Economics \& Management Strategy, 5, pp. 5-24.

Casadesus-Masanell, Ramon, and Pankaj Ghemawat (2006), "Dynamic Mixed Duopoly: A Model Motivated by Linux vs. Windows,” Management Science, 52, No. 7, pp. 1072-1084.

Casadesus-Masanell, Ramon, Barry Nalebuff, and David B. Yoffie, (2007), "Competing Complements," HBS Working Paper.

Casadesus-Masanell, Ramon and Jordan Mitchell (2006), “Irizar in 2005,” HBS case 706-424 and Teaching Note 706-446.

Casadesus-Masanell, Ramon, and David B. Yoffie (2007), "Wintel: Cooperation and Conflict," Management Science (forthcoming).

Christiansen, Evelyn T. and Richard Tanner Pascale (1983), “Honda (A),” HBS case 384-049.

Drucker, Peter (1954), “The Practice of Management,” Harper and Row Publishers.

Evans and Wurster (1997), "Strategy and the New Economics of Information," Harvard Business Review, sep.-oct.

Foster, Richard and Sarah Kaplan (2001), "Creative Destruction from Built-to-Last to Built to Perform,” Financial Times Prentice Hall.

Ghemawat, Pankaj (1991), “Commitment: the Dynamic of Strategy”, The Free Press, New York.

Govindarajan, Vijay and Chris Trimble (2004), "Strategic Innovation and the Science of Learning," MIT Sloan Management Review, Winter.

Guth, William D. (1964), “Crown Cork \& Seal Company (A),” HBS Case 310-013.

Hart, S. and C. Christensen (2002), "The great leap: Driving innovation from the base of the pyramid," Sloan Management Review, 44, 1, pp. 51-56.

IBM Global Business Services (2006), "Expanding the Innovation Horizon: The Global CEO Study 2006," IBM Corporation. 
Kim, Cham, Reneé Mauborgne, and Ben M. Bensau (2002), “Even a Clown Can Do it,” Insead case 302-057-8

Kim, W. Chan, Renée Mauborgne (2005), "Blue Ocean Strategy: How to Create Uncontested Market Space and Make Competition Irrelevant," Harvard Business School Press.

Lee, Hau L. (2004), “The Triple-A Supply Chain,” Harvard Business Review, October.

Lewin, AY. and Volberda, HW. (1999), "Prolegomena on Coevolution: A Framework for Research on Strategy and New Organizational Forms," Organization Science, Vol. 10 (5), pp. 519-534.

London, T. and S. Hart (2003), "Reinventing strategies for emerging markets: Beyond the transnational model.” Journal of International Business Studies, Sept. 2004.

Magretta, J. (2002), “Why Business Models Matter,” Harvard Business Review, May.

Malone, Thomas W. (2004), “The Future of Work”, Harvard Business School Press, Boston.

March, JG. (1991), "Exploration and Exploitation in Organizational Learning." Organization Science, Vol. 2 (1), pp. 71-87.

McGrath, Rita Gunther and Ian C. Macmillan (2005), "MarketBusters: 40 Strategic Moves That Drive Exceptional Business Growth,” Harvard Business School Press.

Porter, Michael (1985), “Competitive Advantage,” The Free Press, Nueva York.

Porter, Michael (1996), “What Is Strategy?,” Harvard Business Review.

Prahalad, C.K. and S. Hart (2002), "The Fortune at the Bottom of the Pyramid," Strategy \& Business, 26, pp. 2-14.

Prahalad, C.K. (2005), "The Fortune at the Bottom of the Pyramid: Eradicating Poverty through Profits," Wharton School Publishing, Philadelphia.

Prahalad, C.K. and Venkat Ramaswamy (2004), "The Future of Competition: Co-Creating Unique Value with Customers," Harvard Business School Press.

Ricart, J.E., M. Enright, P. Ghemawat, S. Hart, and T. Khanna (2004), "New Frontiers in International Strategy," Journal of International Business Studies.

Rindova, V. P. and S. Kotha, (2001), "Continuous 'Morphing:' Competing Through Dynamic Capabilities, Form, and Function," Academy of Management Journal, vol. 44, 6, pp. 12631280.

Rivkin, Jan W. (2000), “Dogfight Over Europe: Ryanair (C),” HBS case 700-117.

Shafer, Scott M., H. Jeff Smith, and Jane C. Linder (2005), "The Power of Business Models," Business Horizons, 48, pp. 199-207.

Thomas, L.G. and R. D'Aveni (2004), “The Rise of Hypercompetition From 1950 to 2002: Evidence of Increasing Structural Destabilization and Temporary Competitive Advantage," WP Oct. 
Varian, H.R. and C. Shapiro (1999), "Information Rules: A Strategic Guide to the Network Economy," HBS Press.

Williamson, Oliver (1985), “The Economic Institutions of Capitalism,” The Free Press, Nueva York.

Yip, George S. (2004), "Using Strategy to Change your Business Model," Business Strategy Review, Vol. 15, 2, Summer.

Zott, C and R. Amit (2006), "Exploring the Fit Between Business Strategy and Business Model: Implications for Company Performance," Working Paper (revised, May).

Zott, C. and R. Amit, "Business Model Design and the Performance of Entrepreneurial Companys," Organization Science (Forthcoming). 


\section{Appendix}

An Example: Irizar

Consider Irizar, a highly successful manufacturer of bodies for luxury coaches, and a member of Mondragón Corporación Cooperativa (MCC), the largest industrial group in Spain. ${ }^{19}$ Under the leadership of Mr. Koldo Saratxaga, Irizar emerged from near-bankruptcy in 1991 to become "probably now the most efficient coachbuilder in the world," according to The Economist Intelligence Unit (2000, page 172). In fact, Irizar's model has received several noteworthy recognitions such as the overall winner of the European Quality Award in 2000 (granted by the European Foundation for Quality Management, EFQM). The company also clinched the title as the best European coach of the year in 2004 with its PB model.

Saratxaga set up a singular business model based on the choices shown in Table A1.

\section{Table A1}

Irizar's Business Model - Main Choices

\begin{tabular}{|c|c|}
\hline Choices & Explanation \\
\hline 1 - Self-managed teams & $\begin{array}{l}\text { All work is done by teams that set their own goals, decide how to organize, choose the team } \\
\text { leader }\end{array}$ \\
\hline 2 - No clocking-in and clocking-out & $\begin{array}{l}\text { Teams decide when to begin work and when to end. There is an understanding that on average } \\
\text { individuals should work } 8 \text { hours per day }\end{array}$ \\
\hline 3 - No hierarchy, no bosses & Flat organizational structure. Three levels only. No bosses, just coordinators \\
\hline 4 - No departments & No formal departments. All work organized through multidisciplinary teams \\
\hline 5 - Open floor plant & $\begin{array}{l}\text { Organization of physical space resembles organization. No walls. All in one level only. No } \\
\text { assigned parking spaces }\end{array}$ \\
\hline 6 - No paid overtime & Teams often work overtime, but receive no additional pay \\
\hline 7 - Distributed decision-making & Most members allowed to make important decisions in Irizar's behalf \\
\hline 8 - Obsession about communication & $\begin{array}{l}\text { All information available to members. Lots of meetings to inform and discuss business } \\
\text { perfomance. Internal publication. General assemblies }\end{array}$ \\
\hline 9 - Workers' cooperative & $\begin{array}{l}\text { Governance structure of organization: a workers' cooperative. Workers own the assets and } \\
\text { make financial contribution (are shareholders) }\end{array}$ \\
\hline $\begin{array}{l}10 \text { - No use of words such as employee, human } \\
\text { resource, wage-earner }\end{array}$ & All individuals treated with absolute respect. All at the same level. No derogatory language \\
\hline 11 - Low-powered (extrinsic) incentives & Pay scale is $1: 3$, amazingly flat \\
\hline 12 - No firing & After tenure is granted ( 3 years probation) nobody is ever fired \\
\hline 13 - One product for all markets & One coach model to serve all markets (all continents) \\
\hline 14 - A Constitution ("Strategic Thoughts") & Document entitled "Strategic Thoughts" is a short Constitution detailing what Irizar is all about \\
\hline 15 - No (detailed) strategic plans & No quantitative plans. Lots of thought on qualitative measure of success \\
\hline 16 - Obsession about the future & $\begin{array}{l}\text { Large effort to foresee how Irizar fits in the future and what needs to be done today to be ready } \\
\text { to compete effectively tomorrow }\end{array}$ \\
\hline 17 - Treat customers and suppliers symmetrically & $\begin{array}{l}\text { Although Irizar is a manufacturing company. It thinks of itself as a "platform" bringing together } \\
\text { suppliers and customers. Great effort put into understanding well customers and suppliers } \\
\text { needs }\end{array}$ \\
\hline 18 - No "stars." No "temps" & Never hire star workers nor temporary workers \\
\hline 19 - No unions & Non-unionized \\
\hline 20 - Avoid repetitive tasks & $\begin{array}{l}\text { Individuals move from team to team as old teams complete tehir assignments. Always doing } \\
\text { varied, new work }\end{array}$ \\
\hline 21 - Celebrate diversity & $\begin{array}{l}\text { Clear understanding that members are all different and cannot be expected to exert the same } \\
\text { amount of effort and be equally committed to the project }\end{array}$ \\
\hline 22 - No evaluations & Nobody is evaluated after tenure \\
\hline 23 - Careful granting of tenure & Three-year probation period. Carefull evaluation of candidates \\
\hline 24 - Look for external recognition (EFQM...) & $\begin{array}{l}\text { Great effort put into making the "Irizar Project" (the business model) known through paricipation } \\
\text { in total quality management competitions such as EFQM's }\end{array}$ \\
\hline 25 - Strict control of expnditures & Careful control of finances \\
\hline 26 - Generalists/Not specialists & Look for generalist, smart and motivated individuals who are not afraid of sharing creative ideas \\
\hline 27 - Leadership by example & Top management commitment to Irizar is shown by setting example of ethical behavior \\
\hline 28 - Heavy use of outsourcing & Most repetitive tasks are outsourced \\
\hline 29 - Young workforce & Average age under 30 \\
\hline 30 - Located in small town: Ormaiztegi & Small/isolated plant in Spain's Basque Country \\
\hline 31 - High prices & Relatively high prices \\
\hline 32 - Profit sharing & Some level of profit (and losses) sharing to complement wage \\
\hline
\end{tabular}

\footnotetext{
${ }^{19}$ Interested readers can find a complete description and analysis of Irizar's business model in Casadesus-Masanell,
} Ramon and Jordan Mitchell (2006). 
Notice that these are all specific choices, not consequences. In particular, we have not included constructs such as "cooperative culture" or "a product for which there is high willingness to pay" because these are not chosen directly, these are consequences of choices, not direct choices. ${ }^{20}$ Figure A1 is a representation of Irizar's business model.

\section{Figure A1}

Irizar's Business Model

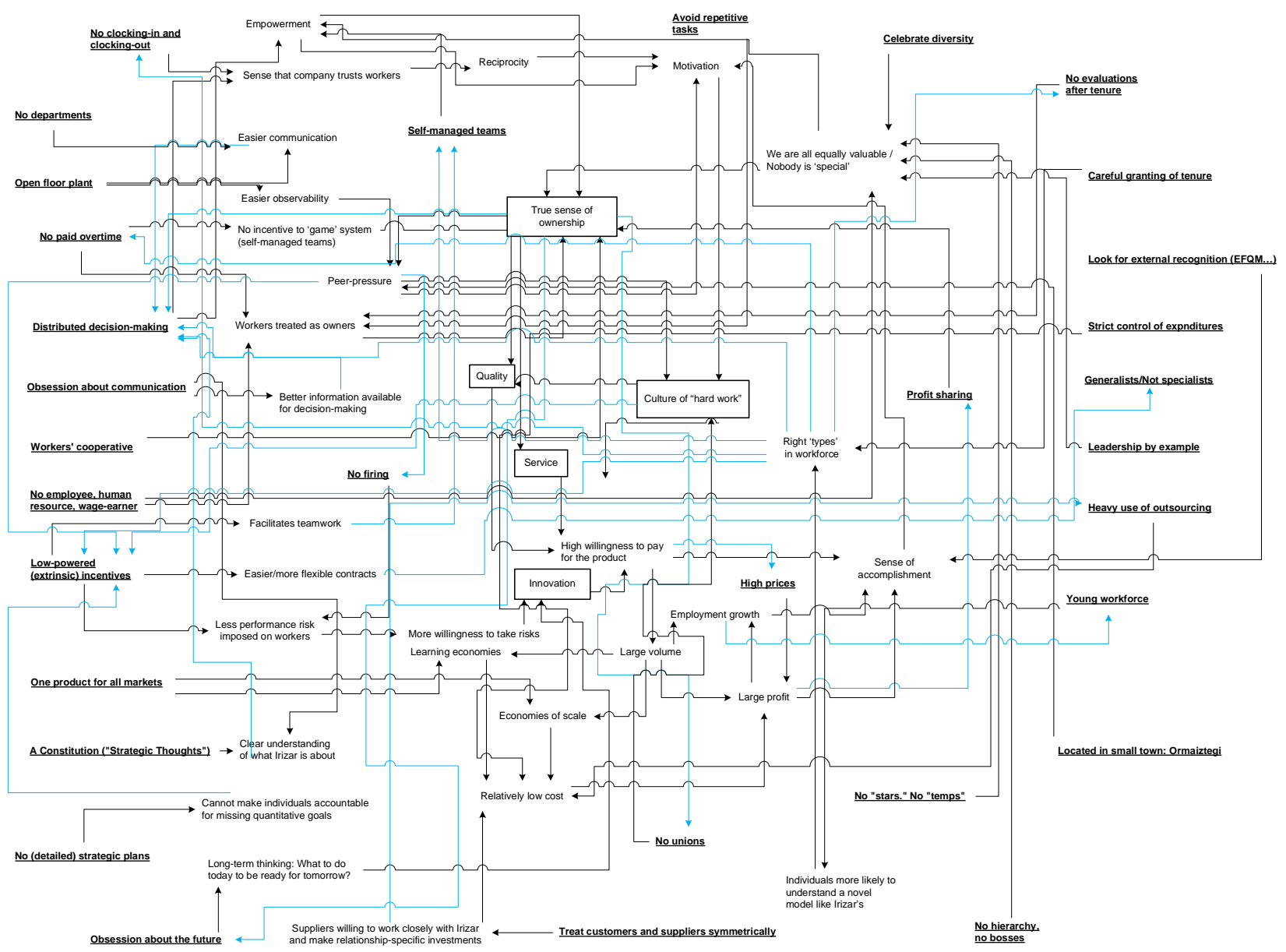

The starting points in the representation are the choices. In the case of Irizar, many key choices are related to aspects of governance. Choices drive consequences, flexible or rigid (in boxes). Finally, the arrows represent theories. We use black arrows to represent theories of consequences derived from choices and blue arrows to represent theories of choices enabled from consequences. Following the choices and consequences one is able to identify the fundamental virtuous cycles that allow Irizar reach its goals.

\footnotetext{
${ }^{20}$ Irizar may aspire to create a cooperative culture or a product for which there is high willingness to pay but these are not direct choices, they are consequences from choices.
} 
Notice the important rigid consequences characterizing Irizar's business model: true sense of ownership, hard work culture, innovation, quality, and service. These consequences imply high willingness to pay for Irizar's motor coaches. The company can then charge high prices which, together with the reasonable costs and large volume, result in high profits. The production of superior products and profit sharing with the employees, who are also owners (workers' cooperative), feed back into the sense of ownership that Irizar's policies reinforce. Overall, Irizar is able to manage a value enhancing cycle that creates increasing value to be shared by the owners-employees, allowing growth and the creation of value-added jobs both in the Basque Country and abroad, making Irizar a tremendous success story.

The business model representation of Figure A1 is quite complex. To better understand Irizar's success, one can look at the business model from a greater distance. Figure A2 shows the same model but identifies the main virtuous cycles. Then, Figure A3 shows Irizar's business model at a higher level of aggregation, presenting only the virtuous cycles, to make as clear as possible the fundamental logic of value creation and capture.

\section{Figure A2}

Irizar's Business Model - Main Virtuous Cycle

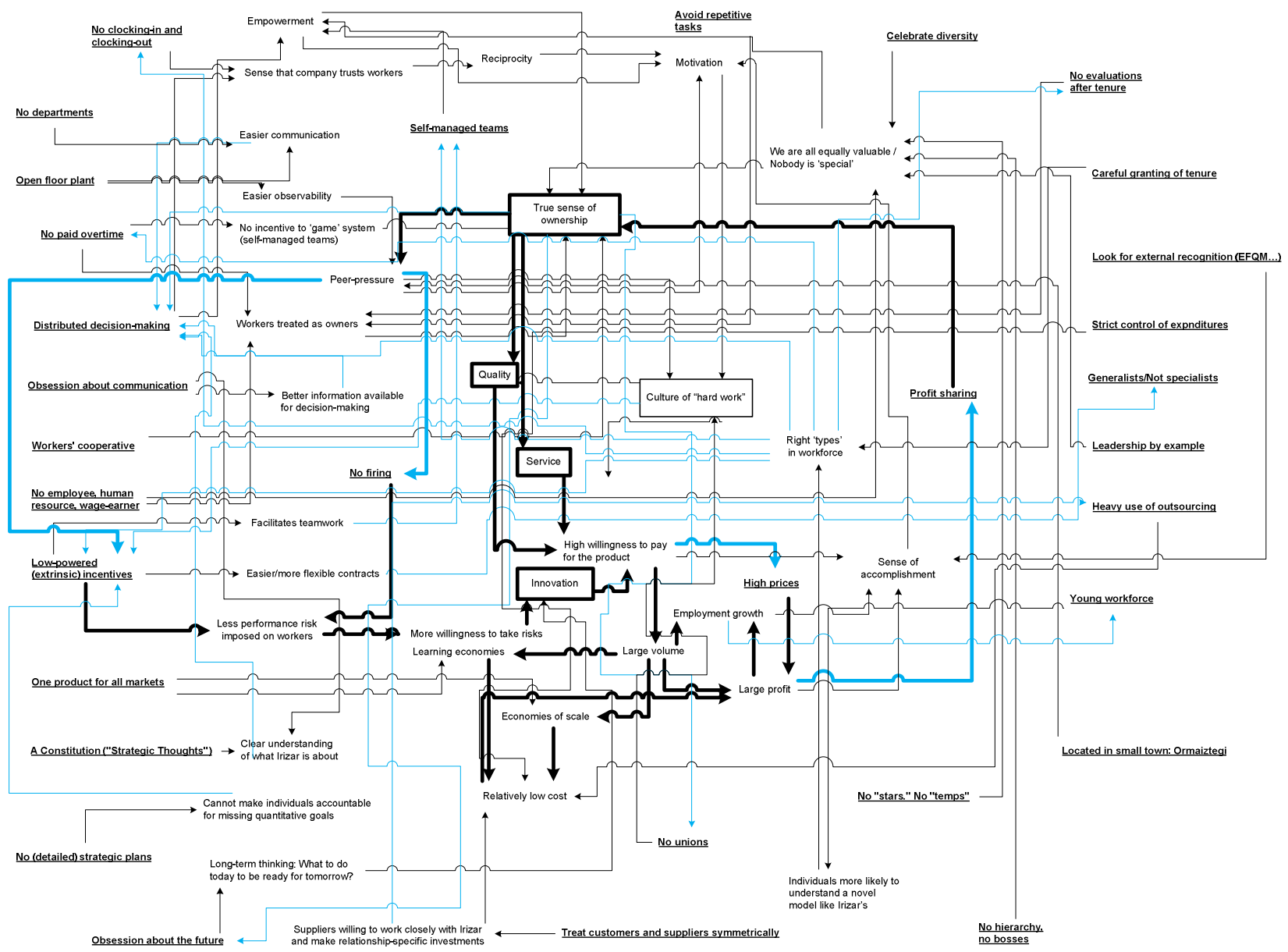




\section{Figure A3}

Irizar's Business Model - Main Virtuous Cycle

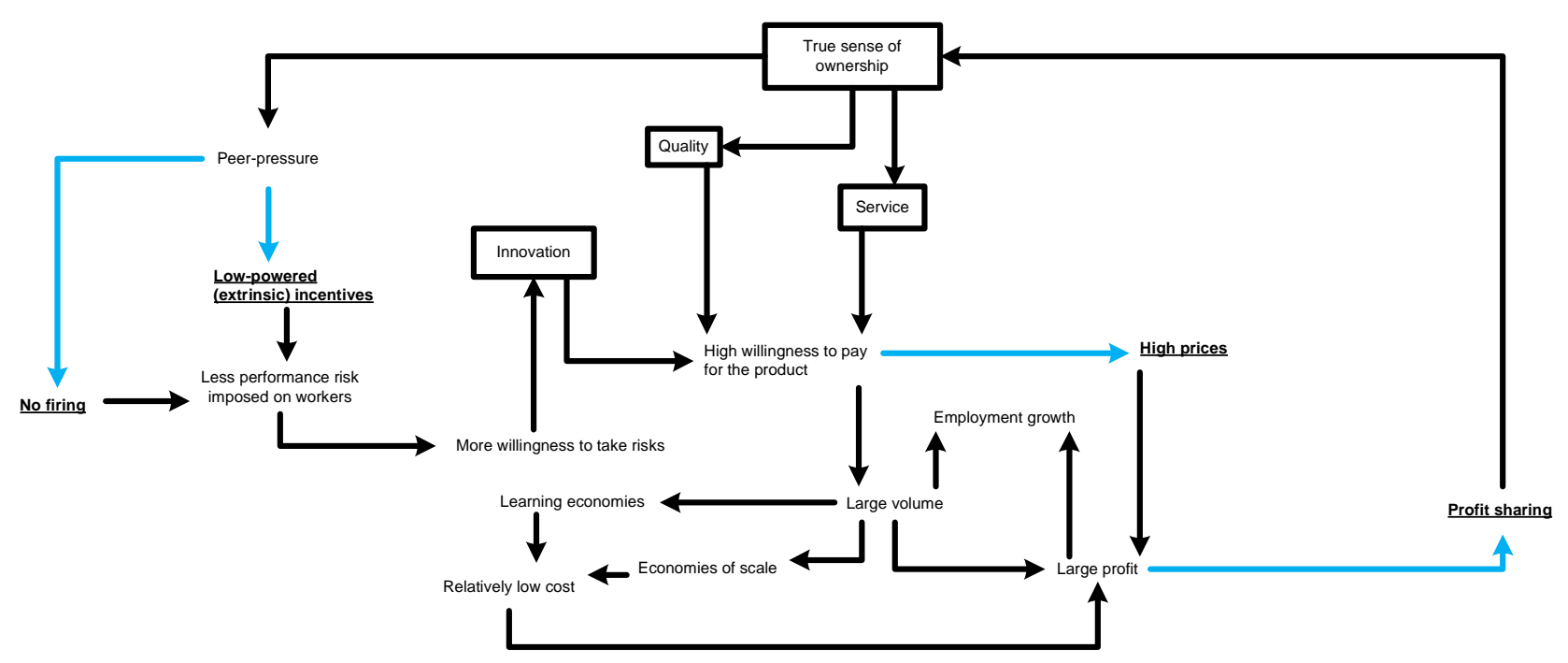

In this representation of Irizar's main virtuous cycle there are four choices only (profit sharing, high prices, low-powered incentives, and no firing policy) but there are many consequences. We should stress that it would have been very difficult to come up with such a representation if all we knew about Irizar were these four choices only. A number of representations are consistent with these four choices. In order for us come up with Figure A3 based on four choices only, we would have had to be very creative in the use of "theories." Figures A1 and A2 allow us to state the theories of Figure A3. That is, we can confidently say that the right theories are embedded in Figure A3 because we know of twenty-eight other important choices in Irizar's business model (see Table A1). Theory selection is refined by considering as many important choices as possible.

Irizar's main objective is the sustainability and growth of high value-added jobs in the Basque Country. To do so, Irizar has developed a model that creates large customer value. The key virtuous cycle connects high willingness to pay with relatively low cost generating high profits with activities related to innovation, service and quality. This allows Irizar to further its mission. To that fundamental cycle, we add all other choices listed in Table A1, with their consequences, to obtain the business model representation in Figure A1. There are alternative ways to understand Irizar's model but most share the same logic. For instance, one can easily identify the rigid consequences that drive most of its competitive advantage as the sense of ownership, innovation, quality, and service, as well as the resulting organizational culture. These strategic assets should be highlighted in any reasonable representation of Irizar's business model. 